\title{
COVID-19: Relato Radiológico de Dois Casos
}

\section{COVID-19: Radiologic Report of Two Cases}

António Pedro Matos¹, João Lopes Dias¹,2, José Sardinha

Autor Correspondente/Corresponding Author: António Pedro Matos [antoniopmatos@gmail.com]

Tv. Castro No 3, 1350-070 Lisboa, Portugal

ORCID iD: 0000-0001-9191-3742

\section{RESUMO}

A evolução da infeção e pandemia SARS-CoV-2 à escala mundial teve um significativo impacto social, económico e nos sistemas de saúde. Através da apresentação de dois casos clínicos, revê-se e discute-se o papel da Radiologia na COVID-19. No enquadramento clínico de cada caso, os achados em tomografia computorizada de tórax serão discutidos.

É importante que todos os médicos estejam conscientes do papel da Radiologia, nomeadamente dos estudos tomografia computorizada para o diagnóstico da pneumonia SARS-CoV-2. Para os radiologistas é fundamental saberem reconhecer os padrões típicos desta patologia.

PALAVRAS-CHAVE: COVID-19; Pneumonia/diagnóstico por imagem; SARS-CoV-2; Síndrome Respiratória Aguda Grave/diagnóstico por imagem; Tomografia Computorizada

\section{ABSTRACT}

The world spread of the infection and pandemic of SARS-COV-2, had a significant social and economic impact, as well as in health systems. Through two case reports, the role of Radiology will be reviewed and discussed. In each clinical scenario the computed tomography findings will be discussed.

It is important that all medical personnel are aware of the role of Radiology, namely the computed tomography studies for the diagnosis of SARS-CoV-2 pneumonia. For the radiologists it is imperative to recognize the typical patterns of this disease. KEYWORDS: COVID-19; SARS-CoV-2; Severe Acute Respiratory Syndrome/diagnostic imaging; Tomography, X-Ray Computed

1. Serviço de Radiologia, Hospital CUF Infante Santo, Lisboa, Portugal. 2. Serviço de Radiologia, Hospital de S. José, Centro Hospitalar de Lisboa Central, Lisboa, Portugal.

Recebido/Received: 08/06/2020 - Aceite/Accepted: 14/06/2020 - Publicado/Published: 30/06/2020

• Autor (es) (ou seu (s) empregador (es)) 2020. Reutilização permitida de acordo com CC BY-NC. Nenhuma reutilização comercial. ${ }^{\circ}$ Author(s) (or their employer(s)) 2020. Re-use permitted under CC BY-NC. No commercial re-use. 

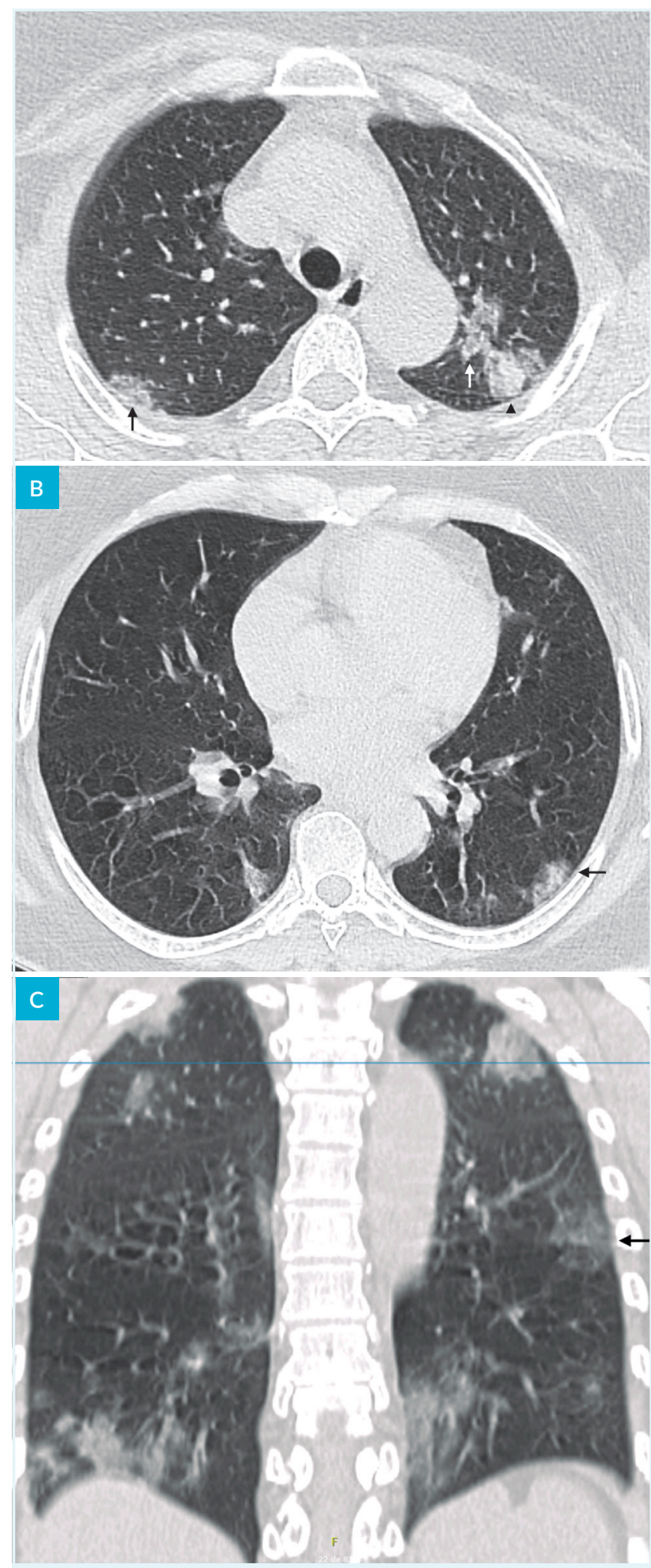

FIGURA 1. Caso 1 - Imagens axiais (a, b) e reconstruções coronais (c) de aquisição TC de alta resolução do tórax sem administração de contraste iodado EV. É possível observar opacidades em vidro despolido (seta preta, a), condensações (ponta de seta, a) e espessamento vascular (seta branca, a), bem como padrão em pedras de calçada (seta preta, b). Estas opacidades distribuem-se de forma periférica e bilateral. Note-se a distribuição coronal das opacidades, bem como a ausência de adenopatias e de derrame pleural.

\section{INTRODUÇÃO}

A 12 de dezembro de 2019, em Wuhan, na China, as autoridades de saúde locais começaram a investigar um surto de pneumonia provavelmente viral, mas de agente específico desconhecido. A identificação de um local de convívio comum à maioria dos infetados - um mercado de animais vivos da cidade de Wuhan - levantou a suspeita de doença zoonótica semelhante a outras epidemias com a síndrome respiratória aguda grave de 2002 (SARS) e a síndrome respiratória do Médio Oriente de 2012 (MERS).

Desde então, assistimos à evolução de uma pandemia à escala mundial, com significativo impacto social, económico e nos sistemas de saúde. ${ }^{1}$ Confirmou-se que uma nova estirpe de coronavírus (SARS-CoV-2) era o agente biológico envolvido, e a doença passou a designar-se por COVID-19.

Devido ao envolvimento predominante do sistema respiratório nesta doença, a avaliação radiológica, como método de diagnóstico não invasivo, foi assumindo um papel fulcral na abordagem inicial e no seguimento destes doentes. ${ }^{2}$

Assim, através da apresentação de dois casos clínicos, este artigo pretende rever e discutir o papel da Radiologia na COVID-19. No enquadramento clínico de cada caso, os achados em tomografia computorizada (TC) de tórax serão discutidos.

\section{CASOS CLÍNICOS}

\section{CASO 1}

Uma doente do sexo feminino, de 52 anos, recorre ao Atendimento Permanente (AP) com quadro de 13 dias de evolução de tosse seca, cefaleias e náuseas, sem febre. Como contacto epidemiológico relevante, apenas a assinalar a filha, com quem vive, igualmente com queixas de tosse. Com antecedentes pessoais de dislipidemia e HTA, destaca-se, na medicação habitual, o atenolol. Apresentava-se, à observação, com bom estado geral, eupneica e com saturação periférica de $\mathrm{O}_{2}$ de $98 \%$. À auscultação pulmonar, sobressaía murmúrio vesicular rude, essencialmente à direita, sem sinais de broncospasmo. Analiticamente, destacavam-se leucócitos de $7900 \times 10^{3} / \mathrm{HL}$ (64\% de neutrófilos e 26\% de linfócitos), D-dímeros ligeiramente elevados (627 ng/mL), LDH de $240 \mathrm{U} / \mathrm{L}$, PCR de 5,4 mg/dL e antigenúrias negativas para S. pneumoniae e Legionella. Foi efetuada gasimetria em ar ambiente, com critérios de alcalose respiratória e hipoxemia: pH 7,49; $\mathrm{pCO}_{2} 31$ mmHg; $\mathrm{pO}_{2} 60$ mmHg; $\mathrm{HCO}_{3}-23 \mathrm{mmHg}$; Sat.O $\mathrm{O}_{2} 93 \%$. Realiza-se zaragatoa nasal para pesquisa de SARS-CoV-2. 
Foi realizada TC de tórax (Fig. 1), que revelou múltiplas opacidades parenquimatosas em vidro despolido, essencialmente periféricas, em número superior a 3 e a mais expressiva com $3 \mathrm{~cm}$ de diâmetro máximo. Coexistiam áreas de padrão em calçada, com vidro despolido associado a espessamento de septos inter e intra-lobulares. De acordo com os critérios da British Society of Thoracic Imaging (BSTI), o diagnóstico de pneumonia por SARS-CoV-2 foi considerado provável, com um nível de gravidade entre moderado e severo.

É então internada com o diagnóstico presuntivo de COVID-19 (posteriormente confirmada por teste de reação em cadeia de transcriptase reversa - RT-PCR positiva), complicada de insuficiência respiratória de tipo 1 , em enfermaria de Medicina dedicada. Inicia tratamento com hidroxicloroquina 400 mg bid no primeiro dia e 200 mg bid nos 7 dias seguintes e azitromicina 500 mg no primeiro dia e 250 mg/dia nos 4 dias seguintes. Clinicamente, verificou-se uma evolução favorável, com resolução sintomática precoce, apirexia e sem necessidade de oxigenoterapia a partir do primeiro dia de internamento $\left(\mathrm{O}_{2}\right.$ a $2 \mathrm{~L} / \mathrm{min}$ por óculos nasais).

Em TC de reavaliação (Fig. 2), os achados radiológicos acompanharam a evolução clínica, tendo-se verificado redução numérica e dimensional das opacidades parenquimatosas. No entanto, notam-se aspetos de pneumonia organizativa, com opacidades lineares subpleurais, demonstrando o habitual padrão evolutivo de resolução do processo infecioso.

Por ausência de condições familiares de isolamento, manteve-se o internamento até negativação laboratorial confirmada. Após três testes de cura por zaragatoa nasal positivos, foram realizadas serologias que confirmaram ausência de IgM e positividade para IgG.

\section{CASO 2}

Um doente do sexo masculino, de 39 anos, recorre ao AP com quadro de febre e contexto epidemiológico relevante (contacto com os pais, ambos positivos para SARS-CoV-2). Como antecedentes pessoais relevantes, destacavam-se tabagismo e seminoma testicular submetido a orquidectomia e quimioterapia. Com RT-PCR inicialmente negativa em zaragatoa nasal, é medicado com azitromicina 500 mg durante 6 dias, sem melhoria significativa, pelo que regressa ao AP por febre alta (TT $39,0^{\circ} \mathrm{C}$ ), mialgias e dorsalgia, sem dispneia ou tosse. À observação, apresentava-se pálido, febril (TT 38,6 C), eupneico, com saturação periférica de $\mathrm{O}_{2}$ de 98\% e auscultação pulmonar normal. Analiticamente, destaca-

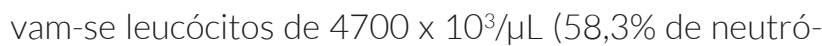
filos e 30,8\% de linfócitos), D-dímeros de 253,2 ng/mL,

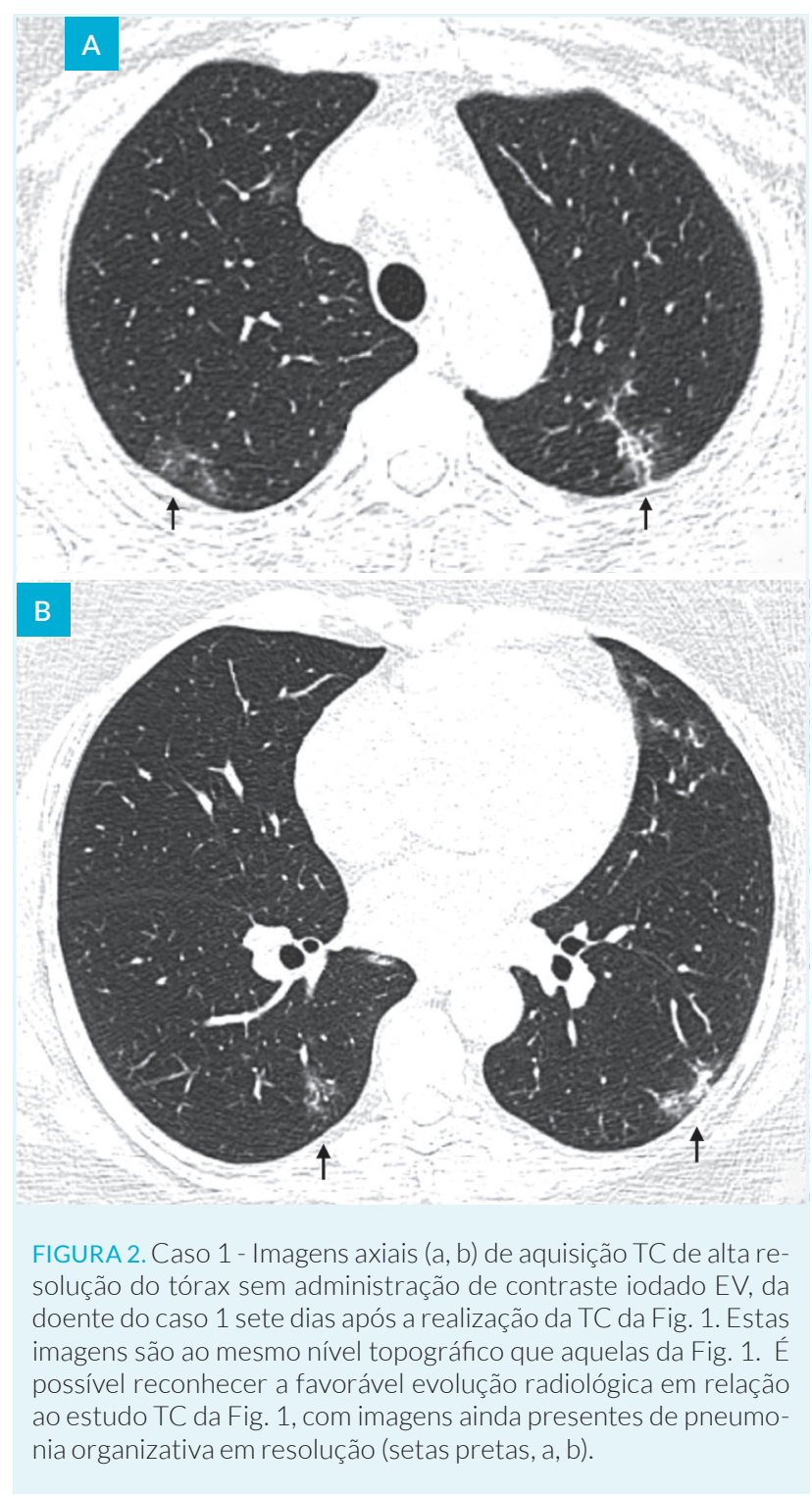

LDH de 146 U/L, PCR de 2 mg/dL e antigenúrias negativas para S. pneumoniae e Legionella. Realiza TC de tórax (Fig. 3), que revela achados suspeitos de pneumonia por SARS-CoV-2, de grau moderado (opacidades nodulariformes em vidro despolido, de predomínio periférico e inferior, algumas com "crazy-paving"), e repete a zaragatoa nasal, desta vez com RT-PCR positiva. Dada a estabilidade clínica e a ausência de dispneia ou toracalgia, tem alta com indicação para manter medidas de isolamento social e tratamento sintomático, com resolução dos sintomas.

\section{DISCUSSÃO}

A deteção precoce da infeção causada pelo SARS-CoV-2 tem sido atrasada pela necessidade de produção em massa e disseminação generalizada de testes de reação em cadeia de transcriptase reversa (RT-PCR). Para além disto, a sensibilidade do teste na prática clínica pode ser 

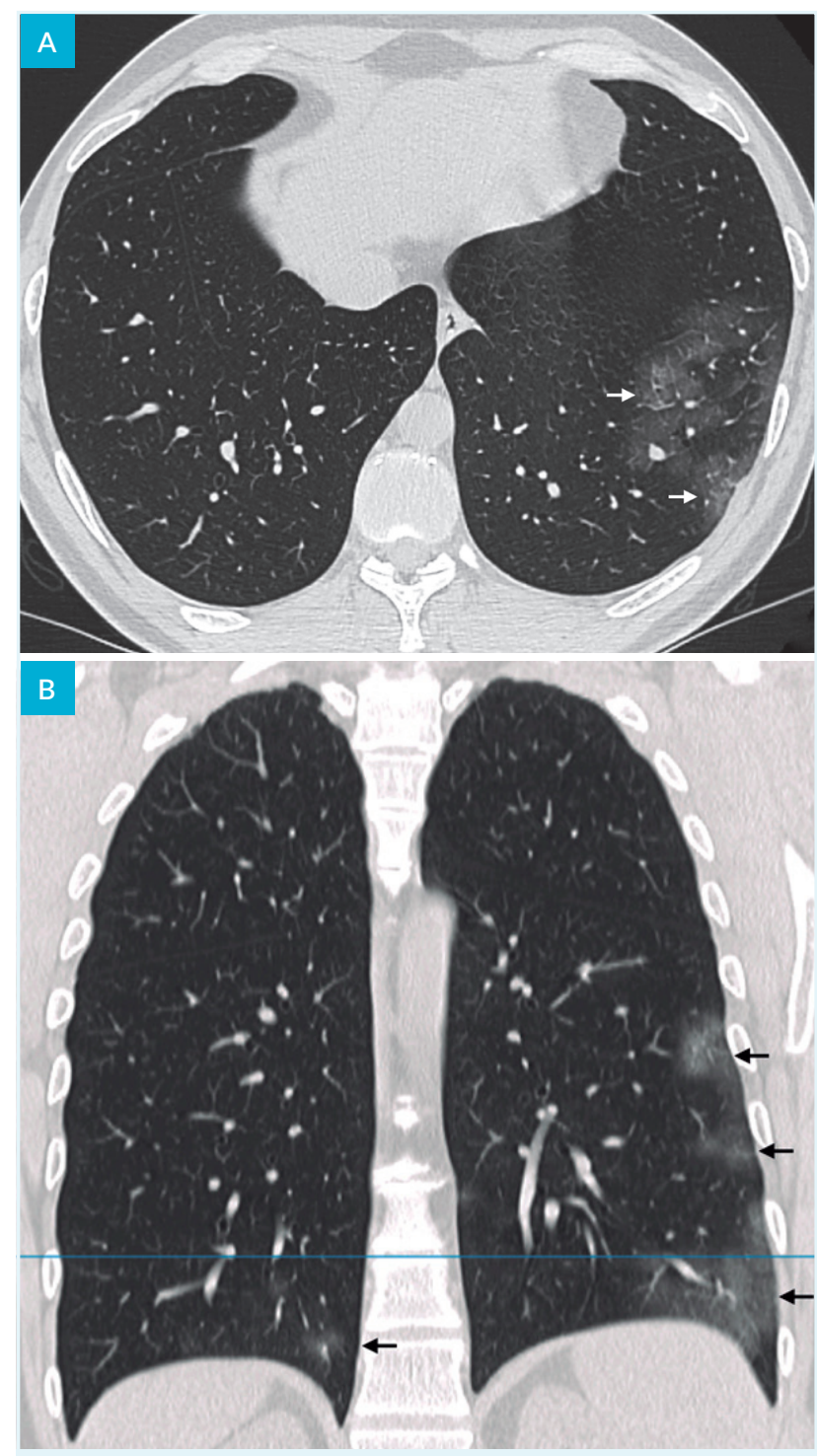

FIGURA 3. Caso 2 - Imagens axial (a) e de reconstrução coronal (b) de aquisição TC de alta resolução do tórax sem administração de contraste iodado EV. É possível observar, em posição periférica e de predomínio na base esquerda, opacidades em vidro despolido, algumas esboçando padrão em pedras de calçada (setas brancas, a). Na imagem de reconstrução coronal é possível perceber a distribuição inferior e periférico das opacidades em vidro despolido (setas pretas, b), bem como a sua bilateralidade, embora de ténue expressão à direita. Note-se, tal como no caso 1, a ausência de adenopatias e de derrame pleural.

afetada por várias variáveis, resultando em falsos negativos frequentes reportados em doentes com achados TC compatíveis com COVID-19, que acabam por testar positivo para o teste.,34 Desta forma, mesmo em casos com resultado de RT-PCR negativo, num ambiente de recursos limitados, os exames radiológicos estão indicados para triagem médica de doentes com suspeita de COVID-19, que apresentem manifestações clínicas moderadas a graves e uma probabilidade pré-teste elevada para a doença. ${ }^{5,6}$ Os exames radiológicos, desempenham assim uma função essencial na triagem e diagnóstico presuntivo, em determinados contextos.
Os casos clínicos apresentados demonstram a utilidade dos estudos TC no auxílio diagnóstico, nos quais os achados radiológicos, no contexto pandémico SARS-CoV-2, foram essenciais para o diagnóstico presuntivo desta infeção viral.

Os TC da pneumonia COVID-19 mostram opacidades em vidro despolido (OVD) (88\%), sejam OVD isoladas ou associadas a espessamento dos septos interlobulares e/ou consolidações. ${ }^{7}$ Outros achados compreendem bronquiectasias, espessamento pleural, padrão em calçada e pneumonia organizativa.' Estes achados são frequentemente bilaterais (87,5\%), periféricos (76\%) e multilobar (78,8\%). ${ }^{7}$

No seu conjunto, estas características das imagens TC encontram-se presentes nos estudos TC dos casos apresentados, demonstrando a utilidade dos mesmos no diagnóstico presuntivo de pneumonia a SARS-CoV-2. Tal como acontece nestes casos, a ausência de derrame pleural e de adenopatias é característico desta patologia.

\section{CONCLUSÃO}

No contexto pandémico e de acesso limitado aos meios de diagnóstico para o SARS-CoV-2, o papel da Radiologia, nomeadamente dos estudos TC do tórax, é fundamental para triar e estabelecer o diagnóstico, tal como estes dois casos o demonstram.

É importante que todos os médicos estejam conscientes do papel da Radiologia, nomeadamente dos estudos TC para o diagnóstico da pneumonia SARS-CoV-2. Para os radiologistas é fundamental saberem reconhecer os padrões típicos desta patologia.

\section{RESPONSABILIDADES ÉTICAS}

CONFLITOS DE INTERESSE: Os autores declaram a inexistência de conflitos de interesse na realização do presente trabalho.

FONTES DE FINANCIAMENTO: Não existiram fontes externas de financiamento para a realização deste artigo.

CONFIDENCIALIDADE DOS DADOS: Os autores declaram ter seguido os protocolos da sua instituição acerca da publicação dos dados de doentes.

CONSENTIMENTO: Consentimento do doente para publicação obtido.

PROVENIÊNCIA E REVISÃO POR PARES: Não comissionado; revisão externa por pares. 


\section{ETHICAL DISCLOSURES}

CONFLICTS OF INTEREST: The authors have no conflicts of interest to declare.

FINANCING SUPPORT: This work has not received any contribution, grant or scholarship.

CONFIDENTIALITY OF DATA: The authors declare that they have followed the protocols of their work center on the publication of data from patients.

PATIENT CONSENT: Consent for publication was obtained.

PROVENANCE AND PEER REVIEW: Not commissioned; externally peer reviewed.

\section{REFERÊNCIAS}

1. Guan WJ, Ni ZY, Hu Y, Liang WH, Ou CQ, He JX, et al. Clinical Characteristics of Coronavirus Disease 2019 in China. N Engl J Med. 2020 (in press). doi: NEJMoa2002032-13.

2. Jin YH, Cai L, Cheng ZS, Cheng H, Deng T, Fan YP, et al. A rapid advice guideline for the diagnosis and treatment of 2019 novel coronavirus (2019-nCoV) infected pneumonia (standard version). Mil Med Res. 2020 (in press). doi: 10.1186/s40779020-0233-6.

3. Fang Y, Zhang H, Xie J, Lin M, Ying L, Pang P, et al. Sensitivity of Chest CT for COVID-19: Comparison to RT-PCR. Radiology. 2020 (in press). doi: 10.1148/radiol.2020200432.

4. Huang P, Liu T, Huang L, Liu H, Lei M, Xu W, et al. Use of Chest CT in Combination with Negative RT-PCR Assay for the 2019 Novel Coronavirus but High Clinical Suspicion. Radiology. 2020;295:22-3. doi: 10.1148/radiol.2020200330.

5. Geoffrey Rubin MD. The Role of Chest Imaging in Patient Management during the COVID-19 Pandemic: A Multinational Consensus Statement from the Fleischner Society. Chest (in press). doi: 10.1148/radiol.2020201365.

6. Xie X, Zhong Z, Zhao W, Zheng C, Wang F, Liu J. Chest CT for Typical 2019-nCoV Pneumonia: Relationship to Negative RT-PCR Testing. Radiology. 2020 (in press). doi: 10.1148/radiol.2020200343.

7. Salehi S, Abedi A, Balakrishnan S, Gholamrezanezhad A. Coronavirus Disease 2019 (COVID-19): A Systematic Review of Imaging Findings in 919 Patients. AJR Am J Roentgenol. 2020 (in press). doi: 10.2214/AJR.20.23034. 